\title{
A roadmap towards a circular and sustainable bioeconomy through waste valorization
}

Article

Accepted Version

Creative Commons: Attribution-Noncommercial-No Derivative Works 4.0

Maina, S., Kachrimanidou, V. and Koutinas, A. (2017) A roadmap towards a circular and sustainable bioeconomy through waste valorization. Current Opinion in Green and Sustainable Chemistry, 8. pp. 18-23. ISSN 2452-2236 doi: https://doi.org/10.1016/j.cogsc.2017.07.007 Available at https://centaur.reading.ac.uk/73361/

It is advisable to refer to the publisher's version if you intend to cite from the work. See Guidance on citing.

Published version at: http://dx.doi.org/10.1016/j.cogsc.2017.07.007

To link to this article DOI: http://dx.doi.org/10.1016/j.cogsc.2017.07.007

Publisher: Elsevier

All outputs in CentAUR are protected by Intellectual Property Rights law, including copyright law. Copyright and IPR is retained by the creators or other copyright holders. Terms and conditions for use of this material are defined in the End User Agreement.

www.reading.ac.uk/centaur

\section{CentAUR}


Central Archive at the University of Reading

Reading's research outputs online 
"From waste to bio-based products: A roadmap towards a circular and sustainable bioeconomy"

Sofia Maina ${ }^{1}$, Vasiliki Kachrimanidou ${ }^{1,2 *}$ and Apostolis Koutinas ${ }^{1}$

${ }^{1}$ Department of Food Science and Human Nutrition, Agricultural University of Athens, Iera Odos 75, Athens, Greece

${ }^{2}$ Department of Food and Nutritional Sciences, The University of Reading, Whiteknights, P.O. Box 226, Reading RG6 6AP, Berkshire, United Kingdom

E-Mails: sofiamaina@aua.gr, v.kachrimanidou@ reading.ac.uk, akoutinas@aua.gr

* Corresponding author: Dr. Vasiliki Kachrimanidou

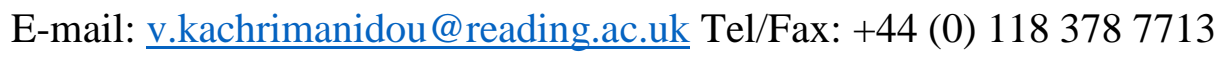




\begin{abstract}
Municipal solid waste and food supply chain waste are globally generated in large quantities from various sectors including various stages of food supply chains, municipalities, open markets and catering services. A prevailing priority in the EU is to stimulate the transition towards a circular economy that fosters the promotion of sustainable and resource-efficient policies for long-term socio-economic and environmental benefits. Common practices for waste management include landfill disposal, anaerobic digestion, composting and wastewater treatment. Recently, new technologies have been introduced to produce value-added products from agricultural residues and food processing side streams. Integrated and holistic approaches for organic waste utilization as industrial feedstocks will boost the transition towards the bio-economy era. The establishment of circular economy would expand and diversify the market outlets of bio-based products. This review provides an overview of the current methods on waste and by-product streams bioconversion to develop biorefinery concepts.
\end{abstract}

Keywords: Circular economy; bio-economy; municipal solid waste; food supply chain waste; biobased products 


\section{Abbreviations:}

MSW: Municipal solid waste

OFMSW: Organic fraction of municipal solid waste

FSCW: Food supply chain waste 


\section{Introduction}

The rapid growth of global population has induced economic development with competitive market policies along with increasing demand for food, feed, fuel and diversified end-products that expanded fossil-based resources requirements [1]. On top of that, an increment of waste per capita is undergoing, entailing multiple environmental and natural resources impacts [2].

Several EU directives have been implemented over the last years to mitigate the negative environmental imprint of services and products throughout the life cycle [3]. A long-term goal has been established by the European Commission for the inauguration of a competitive and resource efficient economy management. Within this framework, the concept and methodology of circular economy and bio-economy have been introduced as system models to overcome the dominant economic development model "take, make and dispose" and administer environmental sustainability. The circular economy has been applied to transform the value chain from linear to closed-loop and enhance the efficiency of resource utilization in order to counterbalance the economic, environmental and societal burdens caused the current linear utilization of resources [4]. The bio-economy relies on the conversion of renewable carbon reserve from agricultural or forestry biomass and organic wastes into diversified end-products and materials, including food, feed, bio-based chemicals, biopolymers, fuels and bioenergy [5].

The core principles of the circular economy are complementary to the bio-economy and should facilitate the recycling and re-use of material directed towards the establishment of integrated sustainable approaches elaborating holistic resource utilization. A shift towards a circular bio-economy is also expected to set a strong perspective on renewed competitiveness, positive economic development and job creation by organizational, social and technological innovation [4]. Regulations and policies should be developed to promote environmentally sound product design and motivate manufacturers to formulate products with reduced environmental impacts. Likewise, the fruitful collaboration of engineers, academics, lawyers, economists and policy makers constitutes a key element to establish synergies between research and stakeholders towards the restructuring of the future economy. Thus, the development of environmentally benign goods and services could develop a sustainable, low-carbon and resource-efficient circular economy [6]. 
The present paper confers an overview of the current waste management for municipal solid waste (MSW) and food supply chain waste (FSCW) and presents a summary of the latest advances in the bioconversion processes. The aim is to present the alternative innovative technologies for the utilization of waste as a resource in the framework of circular economy.

\section{Current waste management of MSW and FSCW}

Excessive waste-stream generation derived from different sectors of the current linear economic model constitutes one of the major societal challenges to be confronted regarding management and disposal. MSW is defined as "wastes produced by households, as well as commercial and other wastes that have similar composition to household wastes". The amount of municipal waste generated consists of waste collected by or on behalf of municipal authorities and disposed of through the waste management system [7]. The amount of MSW accumulated globally per year is approximately 1.3 billion $t$ and is projected to expand up to 2.2 billion $t$ per year by 2025 [8]. The production of MSW in the European Union (28 countries) was estimated at 242.6 million $t$ in 2014 [7], whereas in the USA roughly 258 million t of MSW were generated in 2014 [8]. MSW generation and composition is associated and influenced by socio-economic factors along with the degree of industrialization and the local climate. It has been reported that the waste generation in urban areas will be approximately $1.42 \mathrm{~kg} /$ person/day by 2025 [9]. MSW contains a significant fraction of paper, food waste, wood and yard trimmings, cotton, glass, metals and leather as well as materials deriving from fossil raw materials such as plastics [7]. The organic fraction of MSW (OFMSW) accounts approximately for $46 \mathrm{wt} \%$ of the total municipal waste streams with large content of food waste, kitchen waste and leftovers from residences, restaurants and markets [10]. FSCW is generated throughout the life cycle of different food supply chains including the stages of production of raw materials, the food processing industry and the various distribution chains. FSCW have been classified according to the European Commission into the following categories: “a) food losses: food products lost during the production phase, b) unavoidable food waste: referring to food products lost during the consumption phase and c) avoidable food waste: products that could have been eaten but were lost during the consumption phase" [11]. Specifically, in the EU around 89 million t of FSCW is annually generated and is expected to rise to approximately 126 million t by 2020. Domestic waste and waste from industrial 
processing exhibit the major fragments in the overall FSCW (around 47 million $\mathrm{t}$ and 17 million $\mathrm{t}$, respectively) [12].

Due to the significant quantities of OFMSW and FSCW produced worldwide and the adverse environmental impacts, local, national and European authorities have undertaken various activities towards the implementation of sustainable waste management solutions. The European Commission has elaborated the development of waste management with the implementation of new legislations and policies under a hierarchy of principles, giving top priority to the prevention of waste generation, followed by treatment methods such as recycling, re-use, composting and incineration. According to the last available information about MSW management, considering the total MSW generated in EU, $42 \%$ is landfilled, $38 \%$ is recovered and $20 \%$ is incinerated [7].

Conventional techniques that have been widely applied for the treatment and management of organic waste in developing countries consist of animal feeding, composting, anaerobic digestion, incineration and disposal in landfills [13]. Disposal in landfills causes several environmental issues including greenhouse gas emission, odour production and formation of leachate. Due to the composition of organic waste and the high water content, incineration is an energy demanding and inefficient process that also entails air pollution. Anaerobic digestion and composting constitute the processes where organic materials are converted to low value-added products [13]. On the other hand, thermochemical conversion processes (e.g. pyrolysis, gasification, liquefaction) and bio-chemical conversion methods (e.g. anaerobic digestion, fermentation, microbial fuel cell) convey more advanced approaches for the treatment and management of organic waste in conjunction with the potential to produce value-added bio-based chemicals, polymers, fuels and energy [2,13]. With the deployment of the proper method and systemic approach, different types of biogenic wastes can be converted into diversified types of bio-energy products (eg. biogas, syngas, methane, hydrogen, electricity) targeting various market outlets under the framework of a circular economy.

Circular economy is by definition "restorative and regenerative" [14] demonstrating as a core principle the reuse of available resources and components by prolonging their functionality and worth thereby diminishing waste generation and closing loops. Technological, socio-political and economical restructuring is fundamental to incorporate novel technologies and approaches that will promote the adoption of a circular economy and the closing of loops. The reutilization of 
waste streams as feedstocks for bio-based chemical and polymer production will enable the European chemical industry to use a domestic feedstock reducing the need to import fossil raw materials. The use of domestic feedstocks will also lead to the implementation of innovative technologies leading to increased competitiveness and creation of new job opportunities.

The European industry has started to adopt the strong business cases that could be developed through the utilization of organic waste streams and the application of circular economy principles. Such schemes could lead to improved resource productivity. The feedstock requirements for the European industry could be reduced by 17 - 24\% by 2030 [2] through enhanced resource efficiency that should be achieved along the value chains. Improving the use of resources could reduce the annual expenses of the European industry by more than $€ 600$ billion per year [3]. The application of circular economy principles and resource efficiency is expected to create more than 500,000 new jobs and reduce annual $\mathrm{CO}_{2}$ emissions by more than 400 million $\mathrm{t}$.

A representative example of adoption of renewable resources as feedstock for the production of high grade biofuels is the conversion of ENI's conventional refinery in Porto Marghera (Venice, Italy) into a biorefinery through the Ecofining ${ }^{\mathrm{TM}}$ technology that has been developed by ENI and HoneyWell-UOP [15]. The Ecofining ${ }^{\mathrm{TM}}$ technology includes two stages starting with hydrodeoxygenation of vegetable oils (or microbial oils produced by oleaginous yeast and microalgae or more generally biological feedstocks) leading to the production of a blend of linear C16 - C18 paraffins followed by an isomerisation stage where the paraffin isomers are processed in order to produce fuels that conform to the required specifications. This illustrates a representative example of a major restructuring of conventional processes using fossil raw materials into bio-based processes producing bio-based products in a cost-competitive and environmentally benign manner.

\section{Utilization of OFMSW and FSCW towards a circular economy}

The potential of waste valorization via more attractive alternative solutions such as the extraction and recovery of high value-added compounds and the production of fuels and chemicals has gained much interest in both scientific and public opinion. Under this approach, biorefinery concepts could be a key element for the transition to the circular economy by the development of integrated and multifunctional processes for the exploitation of biomass/waste towards the 
manufacture of marketable intermediates and end-products. A prerequisite for the design of such bioprocesses reckons on economic feasibility in parallel with environmental sustainability demonstrated by lower carbon footprint [16].

The composition of OFMSW widely differs related to the place and time of collection, while the composition of FSCW is dependent on the nature of the original raw material. Generally, OFMSW and FSCW consist primarily of carbohydrates (starch, cellulose, hemicelluloses and soluble sugars such as glucose, fructose and sucrose), proteins, oils/fats and minerals [17, 18, 19]. OFMSW includes food waste, kitchen waste from restaurants, cafeterias and markets, household food wastes whereas it is characterized by high moisture content and high biodegradability. Depending on the type and the composition of organic waste, miscellaneous valuable products could be produced. The extraction of high-value components from various FSCW has been achieved by the implementation of physical, chemical and biochemical processes.

Fruits and vegetables represent a significant portion of the FSCW. Mirabella et al. presented a summary of the different aspects of vegetable and fruit waste valorization for the extraction of bioactive compounds and nutrients [20]. Bioactive compounds including polyphenols, carotenoids, vitamins, antioxidants, flavonoids, fibers and pectin can potentially be used as additives in the food industry, in various pharmaceutical applications and for the production of functional foods. Phenolic compounds have been extracted from apple pomace, citrus peel residues and berries [20, 21]. Pectin has been extracted from apple pomace, citrus peel, sugar beet, sunflower heads, watermelon and waste from tropical fruits and can be used in the food industry as gelling, thickening and stabilizing agent $[21,22]$.

An innovative approach for the valorization of bakery waste for the production of biocolorants has been proposed by Haque et al. [23]. In particular, bakery waste was initially employed to formulate a nutrient-rich bakery waste hydrolysate that was subsequently evaluated for the production of bio-colorants using the fungal strain Monascus purpureus. Natural pigments obtained from biological sources could be applied in the food and textile industries, whereas the natural pigments market is projected to rise from $55 \%$ in 2015 to $60 \%$ of the total food colors market by 2026 [24].

Bio-pesticides, a biological agent for selective control of pest insects, have been produced in semi and solid state fermentation through the valorization of kitchen waste from households, 
cafeterias and restaurants. Zhang et al. [25, 26] achieved the production of up to $862 \mu \mathrm{g} / \mathrm{mL}$ of $\delta$ endotoxin (Bt) biopesticide by Bacillus thuringiensis. Household kitchen waste and domestic food waste have been implemented to secrete various enzymes including glucoamylase, pectinolytic enzymes, lipase, cellulase, glucoamylase-rich media and protease-rich media via solid state fermentation by fungal strains [27, 13].

Agro-industrial, dairy and food processing wastes have been recently used for biosurfactants production [28]. Rhamnolipids, sophorolipids and surfactin demonstrate a wide range of industrial applications including adhesives, flocculating, wetting and foaming agents, deemulsifiers and penetrants. Furthermore, biosurfactants can be used for soil and water treatment as fungicide for agriculture or additive to increase bioremediation activities.

The most common approaches for the valorization of FSCW via microbial bioconversions relate to the production of bioethanol. Numerous reports have proposed methods for the utilization of organic fraction of MSW such as household food wastes, food waste from cafeteria and dinner center, citrus waste, grape pomace, potato peel waste, pineapple waste and banana peel to produce ethanol $[13,29]$.

Several studies have also reported the valorization of FSCW into added-value products that comprise the main feedstock for the production of chemicals, chemical intermediates, biofuelprecursors and biodegradable polymers (Figure 1). Succinic acid, citric acid, lactic acid, butanol and poly(3-hydroxybutyrate) have been widely produced from food waste via fermentation [13, $30,31]$.

Integrated biorefinery concepts have been proposed for the valorization of citrus wastes. The major components of orange peels are soluble sugars, cellulose, hemicellulose, pectin and Dlimonene. Citrus peel residues have been employed for pectin, natural antioxidants, carotenoid and dietary fiber extraction along with providing fermentation substrate for the production of value added products like bioethanol and succinic acid [32].

Flour-rich waste streams generated by various industries including manufacture of bread and confectionery products and food for infants as long as bran-rich wheat milling by products have been valorized for the production of microbial oil. Specifically, wheat milling by-products were used for the production of amylolytic and proteolytic enzymes that were subsequently used for the production of nutrient-rich hydrolysate from flour-rich waste (Figure 2). Hence, flour-rich 
waste hydrolysate was used for microbial oil production by Lipomyces starkeyi and a newly isolated yeast strain belonging to the genus of Metschnikowia [33, 34]. Microbial oil, possessing similar fatty acid composition to vegetable oils, could be used for the production of biodiesel and various oleochemicals such as biolubricants and wax esters. Moreover, waste streams from confectionery industries have been employed for bacterial cellulose production. Bacterial cellulose demonstrates enhanced mechanical properties compared to conventional cellulose thus could find various applications in medical applications and the food industry [35].

Wine less, a by-product generated from wineries, have been used for the development of integrated biorefineries leading to the production of several added-value products including antioxidants, tartate salts, ethanol and nutrient supplements for fermentation process, such as the production of poly(3-hydroxybutyrate) [36].

In most cases, the valorization of FSCW or MSW is based on the development of bioprocesses targeting the manufacture of a single product. Nonetheless, to reassure sustainability and economic feasibility, it is imperative to endeavour the development of biorefineries entailing the production of diversified end-products that will fulfill various market demands towards the establishment of a circular economy.

\section{Conclusions}

Excessive generation of MSW and FSCW could lead to the supply of an important industrial feedstock. Regulations and directives have been established to facilitate the transition from a linear to circular economy that will be enabled through the exploitation of MSW and FSCW. Novel technologies have been developed to optimize exploitation of waste and by-product streams via sustainable approaches. The establishment of integrated biorefineries will lead to the development of innovative bio-based industries, open new market opportunities for bio-based products and achieve efficient resource utilisation. 


\section{References}

1. * P. Ghisellini, C. Cialani, S. Ulgiati, A review in circular economy: the expected transition to a balanced interplay of environmental and economic systems, J. Clean. Prod. 114 (2016) 1132 .

2. S. V. Mohan, G.N. N. P. Chiranjeevi, C. R. Negendranatha, M.V. Rohit, A. Naresh Kumar, O. Sarkar, Waste biorefinery models towards sustainable circular bioeconomy: critical review and future perspectives, Bioresour. Technol. 215 (2016) 2-12.

3. N. Scarlat, J.F. Dallemand, F. Monforti-Ferraro, V. Nita, The role of biomass and bioenergy in a future bioeconomy: Policies and facts, Env. Dev. 15 (2015) 3-34.

4. ** Towards a circular economy: A zero waste programme for Europe, European Commission, Brussels 2014.

5. * A. Székács, Environmental and Ecological Aspects in the Overall Assessment of Bioeconomy, J. Agric. Environ. Ethics. 30 (2017) 153-170.

6. European Commission, Environment. http://ec.europa.eu/environment/gpp/benefitsen.htm (accessed 08.05.2017)

7. European Commission, Eurostat. http://ec.europa.eu/eurostat/statistics-explained/index.php/Municipal_waste_statistics (accessed 10.05.2017)

8. Environmental Protection Agency, Wastes, Municipal Solid Waste https://archive.epa.gov/epawaste/nonhaz/municipal/web/html/ (accessed 05.05.2017)

9. The World Bank, Waste generation http://www.worldbank.org/en/topic/urbandevelopment/brief/solid-waste-management (accessed 04.05.2017)

10. R. Campuzano, S. González-Martínez, Characteristics of the organic fraction of municipal solid waste and methane production: a review, Waste Manage. 54 (2016) 3-12.

11. Food and Agriculture Organization of the United Nations, Food Loss and Food Waste http://www.fao.org/food-loss-and-food-waste/en/ (accessed 04.05.2017)

12. European Commission, Food Safety, Food, Food Waste http://ec.europa.eu/food/safety/food_waste_en (accessed 04.05.2017)

13. * L. Matsakas, Q. Gao, S.Jansson, R. Ulrika, P. Christakopoulos. Green conversion of municipal solid wastes into fuels and chemicals, Electron. J. Biotechnol. 26 (2017) 69-83. 
14. Anonymous, Towards a circular economy: Business rationale for an accelerated transition. Ellen MacArthur Foundation, (2015)

https://www.ellenmacarthurfoundation.org/assets/downloads/TCE_Ellen-MacArthur-

Foundation-9-Dec-2015.pdf (Accessed 20.07.2017)

15. Anonymous, http://news.bio-based.eu/green-refinery/ (Accessed 20.07.2017)

16. N.B.D. Thi, G. Kumar, C.Y. Lin. An overview of food waste management in developing countries: current status and future perspective, J. Environ. Manage. 157 (2015) 220-229.

17. M. Coma, E. M. Hernandez, F, Abeln, S. Raikova, J, Donnelly, T.C. Arnot, M. J. Allen, D. D. Hong, C.J. Chuck. Organic waste as a sustainable feedstock for platform chemicals, RSC, Faraday Discussions. 2017

18. * E. U. Kiran, A.P. Trzcinski, Y. Liu. Platform chemical production from food waste using a biorefinery concept, J. Chem. Technol. Biotechnol. 90.8 (2015) 1364-1379.

19. L. Alibardi, R. Cossu. Composition variability of the organic fraction of municipal solid waste and effects on hydrogen and methane production potentials, Waste Manage. 36 (2015) 147-155.

20. N. Mirabella, V.Castellani, S. Sala. Current options for the valorization of food manufacturing waste: a review. J Clean Prod. 65 (2014) 28-41.

21. A. Baiano. Recovery of biomolecules from food wastes- a review. Molecules, 19 (9) (2014) 14821-14842.

22. C.L.O. Petkowicz, L.C. Vriesmann, P.A. Williams. Pectins from food waste: Extraction, characterization and properties of watermelon rind pectin. Food hydrocolloid, 65 (2017) 57-67.

23. M.A. Haque, V. Kachrimanidou, A. Koutinas, C.S.K. Lin. Valorization of bakery waste for biocolorant and enzyme production by Monascus purpureus. J. Biotechnol. 231 (2016) 5564.

24. Natural Food Colours Market: Demand for Clean Label Products Growing: Global Industry Analysis and Opportunity Assessment, 2016-2026.

http://www.futuremarketinsights.com/reports/global-natural-food-colours-market (Accessed 01.06.2017).

25. W. Zhang, L. Qui, A. Gong, Y. Cao, B. Wang. Solid-state fermentation of kitchen waste for production of Bacillus thuringiensis-based bio-pesticide. BioResources 8.1 (2013) 11241135. 
26. W. Zhang, H. Zou, L. Jiang, J. Yao, J. Liang, Q. Wang. Semi-solid state fermentation of food waste for production of Bacillus thuringiensis biopesticide. Biotechnol. Bioprocess Eng. 20 (2015) 1123-1132.

27. N. Abu Yazid, R. Barrena, D.Komilis,A. Sánchez. Solid-State Fermentation as a Novel Paradigm for Organic Waste Valorization: A Review. Sustainability. 9.2 (2017) 224.

28. S. K. Satpute, G.A. Plaza, A.G. Banpurkar. Biosurfactants' Production from Renewable Natural Resources: Example of Innovativeand Smart Technology in Circular Bioeconomy. MSPE, 25 (1) (2017) 46-54.

29. T. Phuong Thuy Pham, R. Kaushik, G. K. Parshetti, R. Mahmood, R. Balasubramanian. Food waste-to-energy conversion technologies: Current status and future directions. Waste Manage. 38 (2015) 399-408.

30. E. U. Kiran, A. P. Trzcinski, Y. Liu. Platform chemical production from food wastes using a biorefinery concept. J. Chem. Technol. Biotechnol. 90(8) (2015) 1364-1379.

31. F. Girotto, A. Alibardi, R. Cossu. Food waste generation and industrial uses: A review. Waste Manage. 45 (2015) 32-41.

32. C. S. K. Lin, L. A. Pfaltzgraff, L. Herrero-Davila, E. B. Mubofu, S. Abderrahim, J. H. Clark, ... \& S. Thankappan. Food waste as a valuable resource for the production of chemicals, materials and fuels. Current situation and global perspective. Energy Environ. Sci. 6.2 (2013) 426-464.

33. S. Tsakona, A. G. Skiadaresis, N. Kopsahelis, A. Chatzifragkou, S. Papanikolaou, I. K. Kookos, A. A. Koutinas. Valorisation of side streams from wheat milling and confectionery industries for consolidated production and extraction of microbial lipids. Food Chem. 198 (2016) 85-92.

34. S. Maina, C. Pateraki, N. Kopsahelis, S. Paramithiotis, E. H. Drosinos, S. Papanikolaou, A. Koutinas. Microvial oil production from various carbon sources by newly isolates oleaginous yeasts. Eng. Life Sci., 17(3) (2017) 333-344.

35. E. Tsouko, C. Kourmentza, D. Ladakis, N. Kopsahelis, I. Mandala, S. Papanikolaou, F. Paloukis, V. Alves, A. Koutinas. Bacterila cellulose production from industrial waste and byproducts streams. Int. J. Mol. Sci. 16, (2015) 14832-14849.

36. C. Dimou, N, Kopsahelis, A. Papadaki, S. Papanikolaou, I. K. Kookos, I. Mandala, A. A. Koutinas. Wine less valorization: Biorefinery development including production of a generic 
fermentation feedstock employed for poly(3-hydroxybutyrate) synthesis. Food Res. Int. 73 (2015) 81-87. 


\section{Figure captions}

Figure 1 Bioprocessing of food supply chain waste (FSCW) for the production of value-added products

Figure 2 Development of a two-stage bioprocess for food waste valorization to formulate nutrientrich supplements for microbial bioconversions 


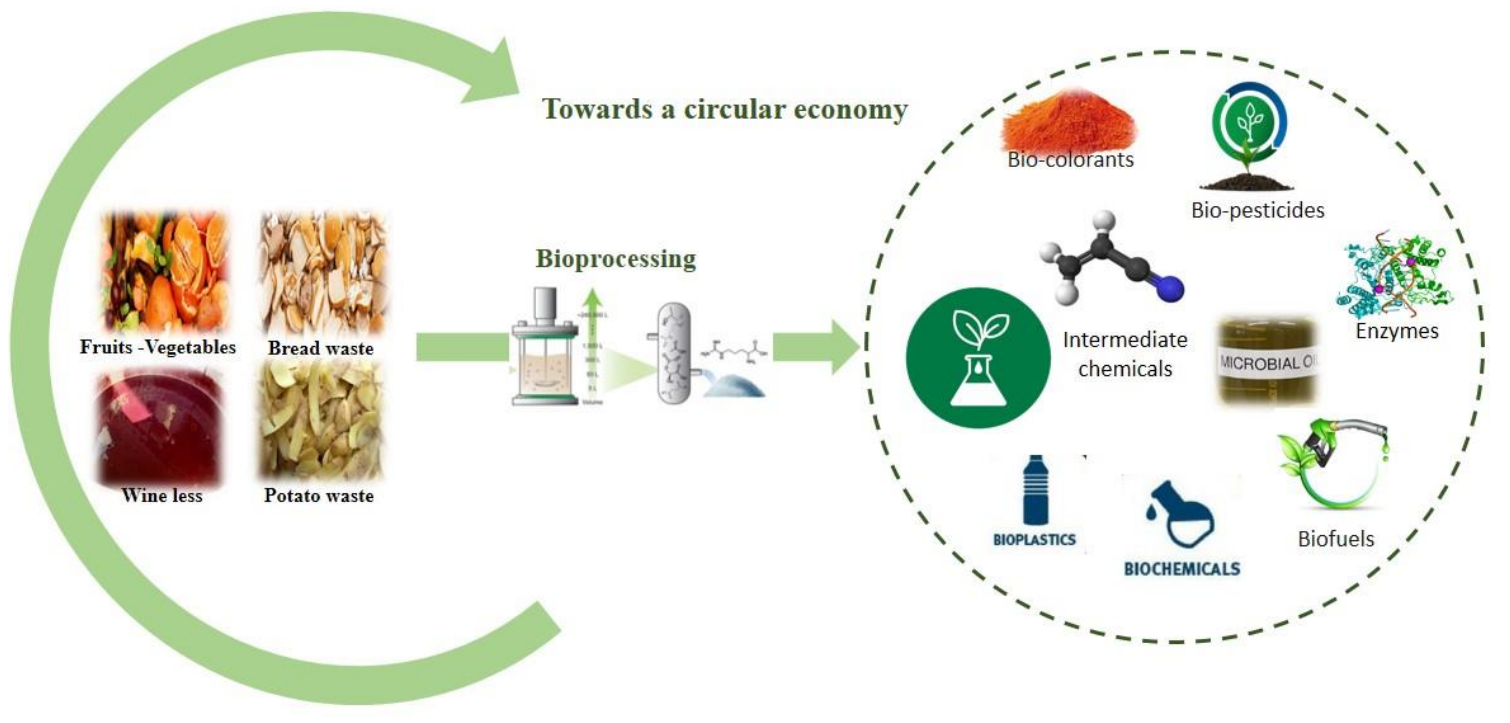

Figure 1 


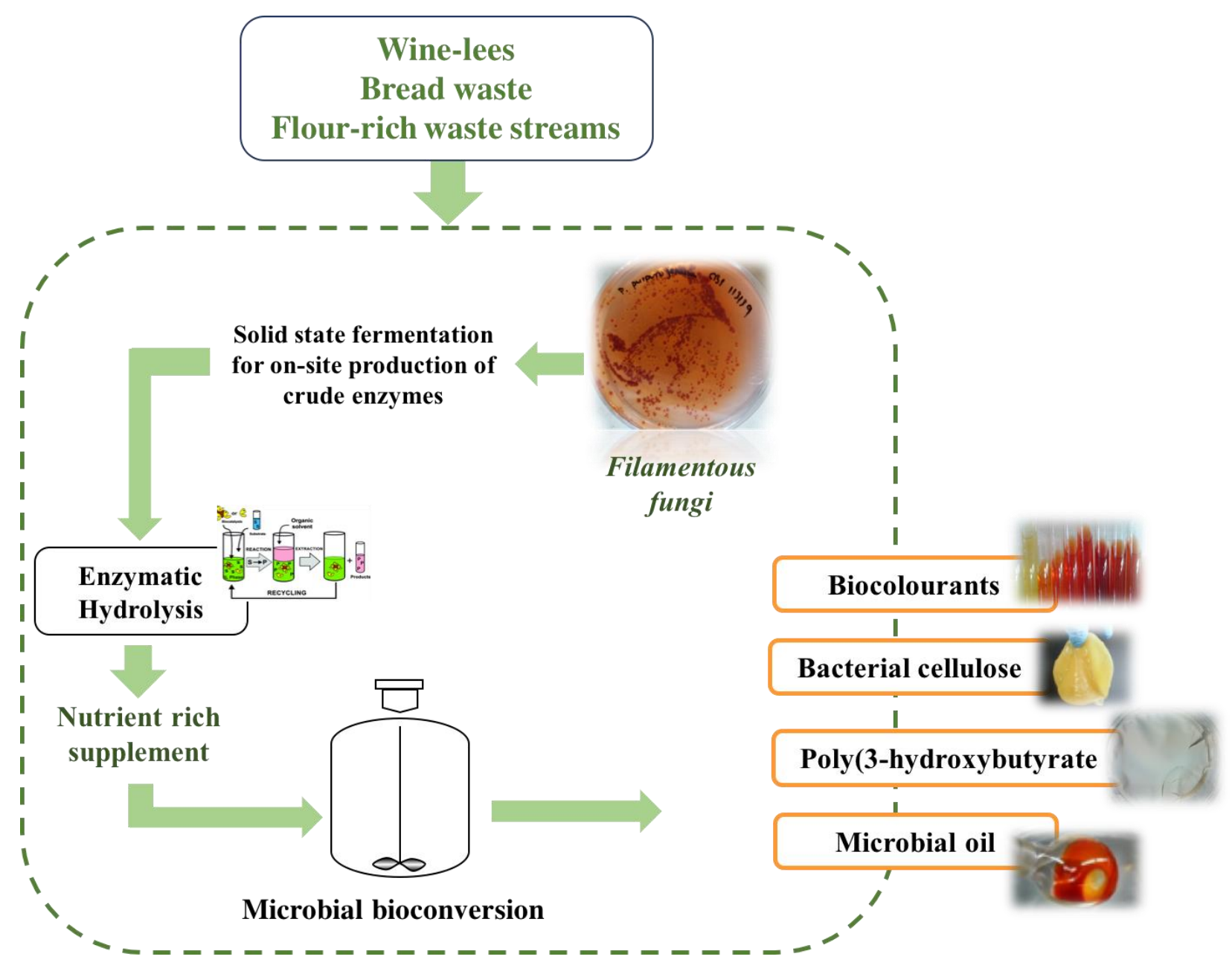

Figure 2 